\title{
Comunicación y territorio: resistencias en el noroeste argentino
}

\section{Communication and Territory: Resistances in the Argentinean Northwest}

\section{Comunicação e território: resistências no nordeste argentino}

María Laura Agüero

Universidad Nacional de Salta - Argentina

\section{Ana Müller}

Universidad Nacional de Salta - Argentina

\section{Páginas Cómo citar}

32-47 Agüero, M. y Müller, A. (2017). Comunicación y territorio.

Recibido

Resistencias en el noroeste argentino. Mediaciones, (19), 32 - 47.

5 de enero de 2017

\section{Aceptado}

22 de mayo de 2017

DOI

http://dx.doi.org/10.26620/uniminuto. mediaciones.13.19.2017.32-47 


\section{Resumen}

En este artículo nos detenemos a pensar en las prácticas, los procesos y los sujetos de la comunicación popular, alternativa y comunitaria del noroeste argentino. Enmarcado en la Investigación Acción Participativa, el artículo exhibe las proyecciones y deseos por ejercer el derecho a la comunicación y los desafíos para repensar de manera colectiva los aportes que cada territorio de la región realiza al campo comunicacional a partir de sus historias y modos de relacionarse afirmando la cultura local como

lugar de enunciación. Esto no solo impacta y transforma los territorios y las luchas históricas de los sectores rurales organizados, sino también nos invita y obliga a reflexionar, investigar, rediscutir y renovar compromisos desde allí.

Palabras clave Derecho a la comunicación, ruralidad argentina, democracia, ciudadanía. 
Abstract

In this article, we reflect upon the practices, processes and subjects of popular, alternative, and community communication in the Argentinean northwest. Within the framework of participatory action-research, the study shows the projections and wishes to exert the right to communication, and the challenges related to re-thinking collectively the contributions of each territory in the region to communication, based on their histories and ways to relate maintaining the local culture as place of enunciation. This does not only impact and transform the territories and the historical struggles of organized rural sectors, but also invites and compels us to reflect upon, research, redebate and renew commitments from there.

\section{Key Words}

Right to communication, Argentinean rurality, democracy, citizenship.

\section{Resumo}

Neste artigo detemos-nos a pensar nas práticas, os processos e os sujeitos da comunicação popular, alternativa e comunitária do nordeste argentino. Enquadrado na Investigação Ação Participativa, o artigo exibe as projeções e desejos por exercer o direito à comunicação e os desafios para repensar de maneira coletiva as contribuições que cada território de região realiza ao campo de comunicação a partir da suas histórias e modos de se relacionar afirmando a cultura local como lugar de enunciação. Isto não só impacta e transforma os territórios e as lutas históricas dos setores rurais organizados, senão também nos convida e obriga a refletir, pesquisar, re-discutir e renovar compromissos desde ali.

\section{Palavras-chave}

Direito à comunicação, ruralidade argentina, democracia, cidadania. 


\section{Los ejes de la carreta ${ }^{1}$}

Trabajamos las prácticas, los procesos y los sujetos de la comunicación popular, alternativa y comunitaria desde el territorio, en el noroeste argentino. Las preguntas y miradas están vinculadas al modelo de desarrollo impulsado desde lo propio, los modos de expresión, las alternativas de lucha y dignidad que surgen desde y en los procesos de comunicación. Los ejes que articulan la comunicación en estos territorios de nuestro norte rural, campesino, indígena y pobre, son el derecho a la comunicación ${ }^{2}$, el horizonte que abre el buen vivir (Contreras, 2014) y la lucha desde la palabra para revertir, o al menos contrarrestar, una histórica de desigualdad, palpable no solo en la comunicación sino también en el acceso a recursos básicos como agua, electricidad, telefonía y conectividad.

Las experiencias que dan origen a este artículo son de comunicación popular, alternativa y comunitaria en el territorio, y documentan cómo las comunidades tomaron la "palabra amplificada» (Martín Barbero, 2003) en el uso de la radio (la más cercana a su oralidad y saber narrativo); ejercieron su «ser ciudadano» (Mata, 2009) manifestando su poder en la acción de existir públicamente y tejieron un colectivo integrando redes en el espacio regional para resistir al nuevo escenario político y económico que atraviesa Argentina (el retorno a las políticas excluyentes, individualistas y neoliberales). Esta lucha política desde y en la comunicación encontró en la Ley de Servicios de Comunicación Audiovisual (2009), hoy intervenida por los decretos n. ${ }^{\circ} 13$ y 267, un impulso inédito de las voces populares.

Es en este contexto en el que el trabajo reflexiona, desde la Investigación Acción Participativa y con un diseño cualitativo, sobre un mapa de experiencias comunicacionales rurales. Exhibe proyecciones y deseos por ejercer el derecho a la comunicación y presenta desafíos para repensar de manera colectiva los aportes que cada territorio realiza al campo comunicacional a partir de sus historias y modos de relacionarse y decirse, «afirmando la cultura local como lugar de enunciación» (Rincón, 2015, p 33). Esto no solo impacta y transforma nuestros territorios, y las luchas históricas de los sectores rurales organizados, sino también nos invita y obliga a reflexionar, investigar, redescubrir, y renovar compromisos desde allí.

Quienes escribimos este trabajo enseñamos e investigamos en la universidad pública y en organismos de ciencia y técnica, pero, antes que todo, somos mujeres que trabajan desde y en lo popular vinculadas al territorio. Creemos

1 En homenaje a la canción Los ejes de mi carreta, de Romildo Risso y Atahualpa Yupanqui.

2 Algunos autores de referencia son W. Uranga, C. Villamayor, M. Mata, A. Barranquero, entre otros. 
que lo vivido y reflexionado aporta a la comprensión de ese fantasma que recorre el continente: el de los condenados de la tierra en defensa de sus territorios ante la avalancha del capital global neoliberal y la modernidad individualista y consumista (Escobar, 1996). Compartimos estas experiencias de activación política con base en las «rarezas» de las identidades en el territorio, esas que se dicen en las muchas historias contadas desde la oralidad y en canciones, coplas, tinkus, chaqueñadas, pin pin ${ }^{3}$. Algunas de esas luchas que la comunicación posibilita cuando se hace desde, por y en el territorio.

Si debíeramos elegir por dónde comenzar, podríamos pensar en las palabras claves que orientan este trabajo de reflexión/acción ubicándonos en la ruralidad: la comunicación, la ciudadanía y la democracia, situadas y con características territoriales definidas. Indagamos y trabajamos junto a organizaciones sociales que se conformaron luchando por el acceso a los derechos y el reconocimiento de su identidad, que las diferencia de otros modos y lugares desde donde decir. Organizaciones y sujetos que incorporaron en sus prácticas la resistencia, expresada en la paciencia y en la firmeza para sostener sus luchas durante siglos. Resistir, generando herramientas de visibilización y pedidos de reconocimiento con leyes puntuales que las involucren y contengan sus necesidades y realidades. La comunicación es parte de un gran abanico.

Somos además parte del Estado y la universidad pública, y desde allí encontramos actualmente muchas dificultades con la nueva gestión de gobierno nacional, fundamentalmente por los cambios de paradigmas e ideologías. Eso modifica y condiciona nuestra tarea, pero sobre todo dificulta el camino de las experiencias de comunicación popular, comunitaria y transformadora, ya que la impronta neoliberal con la que se ejecutan las políticas desde la Alianza Cambiemos no conciben la comunicación como un derecho humano, tal como lo plantea

3 Estilos musicales de diferentes pueblos originarios que componen la cultura del noroeste argentino. el paradigma que dio origen a la LSCA 26.522, por ahora intervenida.

Vivimos en países donde lo urbano tiene una centralidad indiscutible, más aun en los estudios de comunicación donde la mediatización nos atraviesa y define, y las tecnologías se multiplican cada semana. Desde allí pensamos los procesos en la ruralidad situados en los modelos de producción y consumo que nos limitan y definen en relación a las realidades territoriales. Esto tiene que ver con pensar cómo nos alimentamos, cuán soberanos somos de lo que consumimos y producimos. Ponemos atención en conceptos que desde hace décadas circulan en nuestro campo, con una inmensidad de programas y líneas de financiamiento, y con muy poca autocrítica sobre sus significados e impactos. Con mejores intenciones que buenos resultados, 0 transformaciones concretas. No somos las únicas ni tenemos respuestas tan claras, hay diferentes intelectuales que vienen reflexionando en este sentido. Creemos que nuestro aporte es hacerlo desde los territorios, partiendo del hecho que nos movilizan las preguntas, las acciones, la búsqueda y el hacer.

\section{Seguir la huella}

El noroeste argentino es una región sumamente rica y diversa en recursos naturales, en ella encontramos valles, quebradas, sierras, yungas, chaco, con múltiples recursos naturales y diversidad cultural. Sin embargo, es una de las zonas con mayores índices de pobreza del país junto al noreste, con una provocadora desigualdad e injusta distribución de los recursos, entre ellos uno tan básico como la tierra para cualquier familia que trabaja y vive en la ruralidad. Nuestro estudio se ubica específicamente en las provincias de Salta y Jujuy de esta región. Entre las dos contribuyen con el 2,5 \% del PBI nacional y sus estructuras agrarias son diversas y complejas. La agricultura familiar representa en estas provincias el $80 \%$ y $70 \%$ respectivamente del total de las explotaciones agropecuarias que concentran a miles de familias. En proporción con los 
grandes terratenientes, las hectáreas donde viven y producen son muy pequeñas y precarias en la mayoría de los casos $^{4}$. Así y todo, estas comunidades rurales desde hace siglos tienen sus familias, producen sus alimentos, crían sus animales, se organizan para vender lo que sobra y para intercambiar en ferias lo que hacen, manteniendo prácticas culturales e identitarias ancestrales (Alcoba, 2014, p. 129). Desde esos contextos recuperamos las prácticas, los procesos y los sujetos de la comunicación popular, alternativa y comunitaria. Las preguntas y miradas están impulsadas desde «lo propio», los modos de expresión, las alternativas de lucha y dignidad que surgen desde y en esos procesos de comunicación. En este trabajo hacemos una breve aproximación a algunas de estas experiencias. Nazareno y su radio indígena FM Ocan, inaugurada en abril del 2016, luego de muchos años de trabajo y proyección. El Fuerte con la radio Ecos de mi Pueblo, una radio rural y comunitaria que se gestó en el 2013 y se inauguró en agosto de 2015. En 2014 se inició el proceso por una radio comunitaria indígena en la comunidad de Escoipe que hoy se encuentra en proceso de puesta en marcha y gestión bajo el nombre de FM La Voz de la Quebrada.

\section{Escenarios}

El escenario político y comunicacional de Argentina tuvo profundas transformaciones en estos últimos años, lo que podríamos denominar desde Kejval como «el ciclo de institucionalización de la demanda por la democratización de las comunicaciones» (2014, p. 243) iniciado en el año 2009 a partir de la sanción y aplicación de la Ley de Servicios de Comunicación Audiovisual (LSCA). Esta sufrió una herida importante a partir de la asunción del gobierno de Mauricio Macri y la restauración de políticas neoliberales, que incluyeron una serie de

447.975 explotaciones agropecuarias de pequeños productores ocupan 2.269.984 hectáreas, según el cNA 2002, con una superficie promedio de 47 ha/EAPS. Las restantes 11.282 unidades productivas afectan una superficie de 11'401.133 hectáreas, siendo en este caso la superficie promedio de 919 ha/EAPS. decretos modificatorios a la LSCA, lo que afectó incluso lo que se conoció como «el espíritu» de la Ley. Sin embargo, el «cierre» del ciclo 2009 - 2015 nos exige analizar las experiencias de comunicación rural que se desarrollan de la mano de diversos procesos de construcción ciudadana y que, pese al cambio de contexto, continúan llevándose a cabo y al aire.

Existen muchos trabajos que dan cuenta de las implicancias que trajo aparejada la sanción de la LSCA, tanto en el plano nacional como en el ámbito regional $^{5}$, especialmente relacionados con la implementación del sistema argentino de televisión digital terrestre y el fomento de políticas para la producción audiovisual. En este caso, nos preguntamos en qué medida la aplicación de la Lsca reconfiguró el campo de la comunicación popular, alternativa y comunitaria en Argentina y fundamentalmente en el ámbito de la ruralidad, por cuanto que fomentó una interacción diferente con el Estado. Una diversidad de actores se constituyeron por primera vez de manera sistemática en interlocutores válidos para discutir y llevar adelante distintas iniciativas públicas de fomento a la comunicación en general, pero también a la comunicación popular, alternativa y comunitaria, en particular.

Desde el año 2010 se implementaron proyectos que posibilitaron la existencia de emisoras al aire. En tal sentido, describimos y reflexionamos sobre tres experiencias de comunicación que a partir de este escenario encontraron otras condiciones de expresión, nuevos medios, nuevos "territorios» para sus propios discursos. Pensar las radios en la ruralidad implica entender e interpretar sus escenarios.

Los accesos a los servicios y la organización de los tiempos y los espacios no son los mismos que en los centros urbanos. Una parte de las comunidades que integran estas experiencias no cuentan con servicios de luz eléctrica constante. Sus organizaciones

5 Becerra, 2015; Nicolosi, 2014; García Vargas 2014, 2011; García Vargas y Burgos, 2011; Arancibia, 2015. 
están directamente vinculadas con la lucha por la tierra y el territorio desde las reivindicaciones de sus pueblos indígenas o campesinos y para ello la comunicación se ha vuelto otra herramienta en esa lucha. En otras, los medios de comunicación se plantean como puntos de encuentro comunitario entre los que siempre vivieron allí y los que se fueron sumando en los últimos años, en el encuentro entre pobladores y culturas populares, que no necesariamente siempre han estado juntos, ya que en realidad la disputa por el acceso a la tierra los ha puesto en tensión por tener al menos dos modelos productivos y uso de la tierra muy diferentes. Incluso, muchas veces superpuestos. A su vez, dos de esos modelos (el campesino e indígena) entran en tensión con un tercer modelo que concibe la tierra como un bien de uso descartable, como un recurso más, que solo existe como herramienta de rentabilidad y explotación. Para ellos no significa un lugar de pertenencia e identidad, estamos hablando en este caso del modelo empresarial. Pensar en la ruralidad es pensar en estos encuentros, desencuentros y escenarios.

En cada una de las experiencias, hay mucha riqueza para ver, analizar y compartir. Para quienes hacemos de la comunicación no solo nuestro trabajo, sino también nuestro punto de partida para mirar las relaciones humanas se nos hace difícil algunas veces entender que la misma puede estar en un segundo plano en la lista de prioridades de temas para trabajar ${ }^{6}$. Sin embargo, en los procesos populares y rurales esto ha llevado su tiempo. Si bien desde hace más de medio siglo que en América Latina se viene reflexionando desde la comunicación para el desarrollo o el cambio social como lineamientos más trabajados, otras miradas, otros tiempos y arraigos no han llegado con fuerza a las academias y han quedado en los márgenes, invisibilizados ${ }^{7}$.

\section{Las radios indígenas, campesinas y comunitarias, un camino a la integración}

La LSCA contempla que una parte del espectro radiofónico sea destinado a las entidades privadas, estatales-públicas, Iglesia católica y pueblos indígenas, y define estrictamente un 33\% del espectro para que pueda ser utilizado por organizaciones sin fines de lucro. La diferencia entre estos espectros es muy significativa, ya que en principio para acceder a las licencias sin fines de lucro deben concursar y las mismas tienen plazos máximos de uso del espectro, lo que también rige para las de gestión privada. Por otro lado, a las estatales-públicas se le asigna de manera directa autorizaciones sin límite temporal. Hacen uso de lo que es de todos, ya sea por reconocerlos sujetos con derechos preexistentes a la conformación del Estado nacional (es el caso de los pueblos originarios); por ser instituciones del Estado nacional o por ser parte del clero que se ratifica como religión oficial en la reforma de la Constitución de 1994.

Es por esta ratificación por la que también se logra un antecedente fundamental para el reconocimiento de los pueblos originarios como sujetos de derechos y previos que deben ser respetados y reconocidos. La ley dice que se le otorga las

7 María Cristina Mata da cuenta de esta tensión, señalando la paradoja que se produce «mientras el desarrollo de las prácticas comunicativas populares se ha transformado en nuestro continente en estrecha relación con los conflictos del que son expresión y parte, en el campo académico persisten inercias derivadas del desconocimiento de esos procesos cuya historia circula por esos textos insignificantes académicamente» (2015, p. 25). En tal sentido, plantea la necesidad de «sacar la comunicación popular/alternativa de los márgenes académicos» (2015) y afrontar los interrogantes y las tensiones que nos esperan para interpelarnos. 
«autorizaciones a personas de existencia ideal de derecho público estatal, Universidades Nacionales, Pueblos Originarios e Iglesia Católica [ ] a demanda y de manera directa, de acuerdo con la disponibilidad del espectro, cuando fuera pertinente» (LSCA, Art. 37). En el caso de las experiencias que aquí recuperamos, corresponden a ambos tipos y hoy nos encontramos pensando la transformación de Cultura, Política y Comunicación en nuevos medios, nuevos territorios, nuevos discursos.

\section{FM Ocan, Nazareno, Salta}

Desde el 2004 acompañamos una de las experiencias que finalmente pudieron concretar su radio en abril de 2016 (empezamos pensándola años anteriores a la sanción de la ley incluso). Para la gestión de su emisora y equipos la acompañamos fuertemente durante la aplicación de Ley. Hoy se llama radio Ocan y pertenece a la Asociación de Comunidades Aborígenes de Nazareno (Ocan) de la comunidad Kolla. Es una radio de pueblo originario, que tiene características que la acercan a una radio comunitaria (es una función clave que comparten muchas emisoras en la ruralidad, ya que se constituyen como uno de los pocos o únicos medios en sus localidades y la articulación con la comunidad es impostergable). Transmite con autorización para pueblos originarios, en el dial 88.3 de la frecuencia modulada, bajo el lema «Sentirse cerca, estando lejos». Esta radio se encuentra ubicada en el municipio de Nazareno ${ }^{8}$, en el departamento de Santa Victoria Oeste, en la provincia de Salta. La Ocan es la organización que encuentra a 23 comunidades del pueblo Kolla, quienes llevan casi 20 años trabajando juntos y sumándose a

8 Para acceder a Nazareno, desde la ciudad de Salta por ruta nacional n. ${ }^{\circ} 9$ rumbo norte se debe llegar a La Quiaca, provincia de Jujuy; de allí se continúan 120 km en dirección Este hacia Cóndor. En el transcurso de este proyecto, se debe ascender por el Abra del Cóndor a más de $5.000 \mathrm{msnm}$, donde se ubica el límite interprovincial Salta-Jujuy. A partir de allí se continúa por ruta provincial salteña n. ${ }^{\circ} 145$ hasta el Abra de Fundición y luego comienza un rápido descenso hasta los 3.000 msnm, de allí en un valle se encuentra Nazareno (SsAF, 2014, p. 76). otras organizaciones con las cuales conforman el territorio Qullamarka9 . Para la Ocan, contar con una radio significaba sumar a la construcción de un espacio que exprese sus ideas, sus costumbres y sus lenguajes, y que al momento de salir al aire contenga programas elegidos y discutidos por la organización que sean relevantes para la comunidad y contemplen su identidad. En términos de Gumucio-Dagrón y Tufte, la intención es que los miembros de la comunidad se apropien del proceso de comunicación, incluyendo el contenido, la gestión y sobre todo la toma de decisiones, con lo que se busca generar contenidos locales a partir de la pertinencia cultural de sus producciones y el uso apropiado de tecnología, trabajando desde la conformación de redes (Gumucio-Dagrón y Tufte, 2008, pp. 14 - 15).

Pensar la radio como un espacio de participación real es un proceso que se ha venido trabajando desde el año 2005 y que tomó cuerpo en el momento en que la ocan inició la gestión de su medio a través de los concursos en el Fondo de Fomento Concursable para Medios de Comunicación Audiovisual (FOMECA) que la AFsca creó para acompañar y fortalecer a los medios de comunicación comunitarios. Es en este contexto donde el pueblo de Nazareno ve la oportunidad de concretar el viejo sueño de la instalación de una radio que contuviera a las comunidades que rodean la región del Qullamarka, que se escuche y se haga escuchar. A partir del diseño de cuatro proyectos FOMECA, la ocAn obtuvo su estudio de transmisión, se pagaron capacitaciones a comunicadores sociales, operadores técnicos, productores de radio, y sostuvo sus recursos humanos con el pago de honorarios para producir programas de diverso contenido, financiando un programa informativo

9 Qullamarka es la máxima organización como sistema de gobierno a nivel del pueblo Kolla que coordina a las Organizaciones y Comunidades Kollas autónomas de Salta, nucleada por las siguientes organizaciones: la Unión de Comunidades Aborígenes Victoreñas, la Asociación de Comunidades Aborígenes de Nazareno, el Consejo Indígena Kolla de Iruya, la Comunidad Indígena Alta Cuenca del Río Lipeo Toldos y la Comunidad Indígena del Pueblo Kolla Tinkunaku. 
semanal. Los proyectos concursados y ganados se encontraban en las siguientes líneas: Equipamiento (2014 y 2015), Gestión de Medios Comunitarios (2014) y Producción de Contenidos (2015).

Dentro de este proceso de construcción comunicacional surgió la necesidad de discutir cómo llevar adelante dicho proceso, la utilidad de la radio y las articulaciones para lograr un bienestar común que defienda los derechos de las personas y resuelva diversos conflictos que la comunidad atraviesa, como por ejemplo la problemática de las tierras. Esto es lo que comúnmente llamamos el proyecto político comunicacional. En este marco organizativo, a partir del trabajo en red con la Mesa de Comunicación Popular de Salta y Jujuy ${ }^{10}$ se dio la posibilidad de que diversas instituciones como la Universidad Nacional de Salta, Radio Nacional Salta, Secretaría de Agricultura Familiar, AFSCA y otras desarrollaron diferentes actividades de acompañamiento y capacitación.

De esta forma se pusieron en marcha encuentros, charlas, talleres y asambleas, para decidir cómo y quiénes iban a gestionar el medio. En paralelo, la Ocan participó de la mayoría de las convocatorias y encuentros realizados a nivel nacional, y entabló relaciones con organismos nacionales, provinciales y con otras organizaciones sociales. A su vez, fue relacionándose con otras organizaciones y comunidades de diferentes etnias que estaban atravesando el mismo proceso. Esta estrategia de coordinación permitió generar redes de trabajo, intercambiar colectivamente y nuclearse con otras radios rurales que también estaban surgiendo durante la aplicación de la LscA.

\section{FM Ecos de Mi Pueblo: El Fuerte}

FM Ecos de mi Pueblo se inauguró el 11 de agosto de 2015. Es una radio comunitaria ubicada en la

10 La Mesa de Comunicación de Salta y Jujuy es un espacio de articulación integrado por organismos nacionales y organizaciones sociales cuya finalidad es facilitar los procesos de comunicación popular rural en las provincias de Salta y Jujuy. localidad de El Fuerte, Jujuy. El proyecto nace originalmente desde la escuela secundaria, a partir de la iniciativa del Profesor Teréforo Cándido y los estudiantes. Luego de una serie de reuniones mantenidas por vecinos del pueblo durante el 2013, directivos escolares, docentes y autoridades políticas, entablaron vínculos con organismos públicos para trabajar sobre las tres áreas muy diversas: turismo, agricultura y ganadería, y comunicación comunitaria. En este marco, un grupo de jóvenes y adultos de El Fuerte tuvieron la posibilidad de acceder a capacitaciones laborales para promover el desarrollo de estos proyectos productivos, donde toma relevancia el proyecto de la radio comunitaria. El grupo que conformó el área de comunicación comunitaria tuvo el acompañamiento de diversas instituciones que integran la Mesa de Comunicación de Salta y Jujuy y de la Federación Argentina de Radios Comunitarias (FARCO).

A mediados del 2014, se realizaron capacitaciones y desde la Mesa se gestionó la articulación con nuevos actores. Un momento clave para revertir cierta pérdida de interés por parte del grupo de jóvenes que participaban del proyecto de la radio (ante los problemas que se suscitaron a partir de diversas trabas burocráticas que dificultaron la llegada del equipamiento y la discontinuidad del acompañamiento de los talleres) fue la participación en el III Encuentro de Comunicación en los Territorios ${ }^{11}$. Allí se vislumbró más claramente la posibilidad de concretar el anhelo de la radio Ecos de mi Pueblo, que, como sostienen sus protagonistas: «es mucho

11 Los Encuentros de Comunicación en los Territorios promovidos por el INTA reúnen experiencias de comunicación, de todo el país, que acompañan procesos de desarrollo local. En octubre de 2013 se realizó el primer encuentro en el Espacio Memoria y Derechos Humanos (Ex Esma) en la ciudad de Buenos Aires. El segundo se dio en el marco del Congreso Latinoamericano y del Caribe de Educación, Comunicación y Políticas Públicas en el Territorio realizado en Goya, provincia de Corrientes, durante el año 2014. El tercer encuentro se realizó en 2015 en el Valle de Luracatao, en la provincia de Salta, y fue organizada por las Comunidades Unidas de Molinos (cum), INTA y la Mesa de Comunicación Popular de Salta y Jujuy. El cuarto encuentro se realizó en Jáchal, San Juan, en 2016. El último, realizado en 2017, sucedió en El Fuerte, Jujuy, y fue coordinado por radio Ecos de Mi Pueblo. 
más que una radio, es un derecho conquistado, el derecho fundamental de comunicarnos y ampliar nuestras voces, el derecho de comunicar nuestra visión del mundo, de la historia, nuestra forma de producir alimento y nuestra cultura». Es un emprendimiento de vecinas y vecinos de El Fuerte que, agrupados en la organización Nativa, definen en una gestión colectiva la administración, el mantenimiento y el uso de la radio. Ecos de mi Pueblo es también parte de las radios que en todo el país se han encendidos a partir de las luchas sociales para tener diversidad de voces, que en parte se materializaron en la sanción de la Ley 26.522 y las cuales necesitan del apoyo del Estado para la implementación de políticas públicas para fortalecerlas y acompañarlas en sus procesos.

\section{FM La voz de la Quebrada, quebrada de Escoipe}

Esta experiencia nació en los márgenes de los tiempos cuando el Estado era garante y promotor de la comunicación como un derecho. Y desde este lugar siguió gestionando su radio con fuerte identidad y mucho trabajo en la definición del proyecto político, pero aún sin equipos para transmitir. ${ }^{12} \mathrm{~A}$ mediados de 2014 las asociaciones de los diez parajes que integran esta quebrada acercaron una nota al Instituto Nacional de Tecnología Agropecuaria (INTA) solicitando acompañamiento para la gestión de una radio comunitaria. Este pedido no es casual, fue producto del contexto político, social y cultural de nuestro país, que venimos comentando líneas más arriba.

Viven en la quebrada de Escoipe ${ }^{13}$ aproximadamente unas 380 familias con actividades productivas

\footnotetext{
12 El 19 de junio de 2017 nos comunicaron que el proyecto para la compra de equipamiento e instalación de la radio FM ya fue aprobado.

13 La quebrada de Escoipe pertenece al departamento de Chicoana, se encuentra a $60 \mathrm{~km}$ de Salta Capital, y se accede por la ruta provincial $n .^{\circ} 33$. Se encuentra a $2.700 \mathrm{msnn}$, abarcando los parajes de Potrero de Díaz, El Nogalar, Agua Negra, La Yesera, San Fernando de Escoipe, El Sunchal, La Zanja y el Rodeo, El Maray, Maraycito, San Martín y Pie de la Cuesta en la provincia de Salta.
}

vinculadas a economías familiares de autoabastecimiento y venta de excedentes. A pesar de su cercanía con la capital de la provincia, esta zona se encuentra, como tantas otras, en situación de aislamiento, debido a la falta de acceso a servicios básicos como energía eléctrica, telefonía y posibilidades de conectividad. Al grupo inicial se sumaron representantes de todos los parajes, principalmente jóvenes, y las asociaciones y organizaciones, porque entendieron la radio como una herramienta para fortalecer su identidad: «Nos abrirá nuevos horizontes, nos unirá en el aire, porque nos va a permitir poner en valor nuestra identidad. Queremos transmitir quiénes somos y nuestra mirada de la vida en el campo»" ${ }^{14}$. Así esta radio sin radio empezó su proceso con formación, discusión, y aprendizaje acompañada también por los organismos integrantes de la Mesa de Comunicación de Salta y Jujuy, actor clave en estos territorios.

A pesar de la incertidumbre que se vivió en temáticas vinculadas a la comunicación después de diciembre de 2015, estas comunidades decidieron continuar con su proyecto. El encontrarse con otras experiencias (ya sea desde la Mesa, la participación en la Red de Radios Rurales, los Encuentros de Comunicación en los territorios) les dio un importante impulso y la confianza necesaria para continuar el camino a la radio propia. En dos años que lleva el proceso, se gestionaron proyectos para ello. Se hicieron producciones comunicacionales vinculadas a la comercialización de productos de la zona; se realizaron emisiones de radio abierta La Voz de la Quebrada en las ferias y eventos; participaron en capacitaciones de sostenibilidad de medios, de locución y de producción radial con otras radios y otros espacios; se gestionó una biblioteca de comunicación comunitaria, y así la radio se fue insertando en la vida y las prácticas de la comunidad de la Quebrada.

14 Taller realizado el 09 de abril de 2015 en el paraje La Zanja, Quebrada de Escoipe con los representantes de las organizaciones y comunidades en donde se trabajó el proceso de dediniciòn del proyecto polìtico de la radio de Escoipe. Esta frase es una de las respuestas a la pregunta ¿por qué queremos llevar adelante un proyecto radiofónico? 
En este caso se puede continuar a pesar del cambio de políticas, porque no es una experiencia aislada, sino que hay muchos actores que acompañan, que intervienen, lo que se apoya en la fuerte la convicción de la comunidad de contar con un espacio propio desde en donde decir.

\section{(Re) Crear el texto}

Actualmente nos encontramos ante la puja por el lugar de los medios y de disputa entre las concepciones que plantean la comunicación como un derecho o un negocio. En este escenario encontramos puntos comunes: la ruralidad y la articulación en estos territorios del derecho a la comunicación frente a modelos hegemónicos; la lucha desde la palabra para revertir - 0 al menos contrarrestaruna histórica desigualdad palpable en el acceso a recursos básicos. No tenemos dudas de que estas experiencias, al igual que otras tantas, buscan contribuir y fortalecer procesos en permanente transformación y disputa, integrando redes en el espacio regional y nacional para resistir al nuevo escenario político y económico. Organizaciones que siguen luchando por sus derechos al mismo tiempo que los están ejerciendo también desde la comunicación popular, alternativa y comunitaria.

La comunicación popular no se define centralmente por el tipo de medio o soporte técnico, ni la metodología utilizada para su producción, puesto que lo que en realidad caracteriza a estas experiencias es «la búsqueda de una transformación consustancial de las normas de intercambio simbólico, de la producción de sentido, porque las reconoce como aspectos configurantes del tramado social que busca alterar»" (Mata, 1987, p. 218). Estamos inscriptas en la tradición latinoamericana de los estudios de comunicación, y allí el carácter «alternativo» no refiere a la multiplicidad de opciones posibles, ni al grado de innovación estética de las prácticas, sino a su intención alteradora; es decir que hablamos de alternativo por cuanto que alterador de un sistema de cosas dadas, por cuanto que intento de construcción de otra situación política, económica y social para los sectores subalternos (Mata, 1994, p. 18). Por otra parte, creemos que lo «popular» no nombra ninguna esencia, ningún principio identitario a proteger; lo "popular» identifica a unos sectores sociales subalternos, es decir, privados de poder, despojados de poder de decisión en muchos terrenos (Mata, 1988, pp. 2 - 3), en nuestro trabajo y principalmente en las experiencias, los sectores rurales organizados. Cuando hablamos de comunicación popular y de radios «sin fines de lucro» y/o autorizaciones de pueblos indígenas, estamos recuperando experiencias rurales que están integradas por organizaciones con distintos recorridos, en muy diferentes geografías, pero con rasgos similares.

Estos sectores se reconocen y son reconocidos como "privados de poder, despojados de poder de decisión en muchos terrenos» y muchos derechos. En este caso nos interesa mirar qué hicieron desde y con la comunicación. En las tres experiencias han tomado la decisión de tomar la palabra, para «hablar y decir el propio mundo y decirse a sí mismo" (Martín Barbero, 2003, p. 29). Y es que a través de la palabra se encuentran como sujetos pertenecientes a la historia, y por tanto con historia. Poder decir(nos) facilita emancipar(nos), independizar(nos) de un discurso impuesto, recrear el propio texto con nuestras palabras, no sólo diciendo sino además posibilitando que nos escuchen y al mismo tiempo nos escuchemos. Como sostiene Martín Barbero,

hablar no es sólo servirse de una lengua sino poner un mundo en común, hacerlo lugar de encuentro. El lenguaje es la instancia en que emergen mundo y hombre a la vez. Y aprender a hablar es aprender a decir el mundo, a decirlo con otros, desde la experiencia de habitante de la tierra, una experiencia acumulada a través de los siglos. (2003, p 31).

Estos intercambios son procesos de educación, vínculos establecidos y ejercidos desde la educación 
popular. Estas experiencias de comunicación se suman a todas aquellas que intentan romper la lógica del discurso único y el modo único de decir.

Nos permite leer la trama, la historia de los procesos colectivos de los movimientos sociales, recuperando la mediación de la historia para pensar el funcionamiento actual de los procesos de comunicación. Concebimos la comunicación como práctica que nos sirve para entender la realidad en donde nos encontramos, para intervenir en ella, transformándola. Sostenemos que los procesos rurales que acompañamos, y que forman parte de lo que entendemos por comunicación popular y comunitaria, responden y dan cuenta de procesos en los que se articulan la cultura, la comunicación, la educación y la ciudadanía. Estos diferentes actores se posicionan como transformadores de su medio, proponiendo que entren en juego sentidos, saberes y prácticas nuevas a partir de la propuesta de generar y fortalecer espacios de comunicación que ayuden a solucionar los problemas que existen en sus territorios. Sujetos ciudadanos, a decir de Clemencia Rodríguez siguiendo a Chantall Mouffe. Sujetos que, en sus propios territorios, asumen porciones de poder para transformar su lugar, su realidad, "para ir haciendo que su comunidad se parezca más y más a su visión de futuro, a la utopía» (Mouffe, 2011, p. 44). Sujetos comunicadores, que conforman y forman sus medios (materializados en este caso en sus radios) como herramientas desde donde deconstruir y reconstruir y legitimar sus identidades locales, "desde donde proponer visiones de futuro sostenibles, enredadas con lo global desde una perspectiva local» (Rodríguez, 2011, p. 47).

Asumirse como sujetos políticos de un territorio es luchar en el escenario público, desde sus voces y lugares de enunciación que se constituyen contrahegemónicas, dar cimiento y fortalecer los procesos de participación y democracia. ¿Y cómo lo ven los propios protagonistas? Se lo preguntamos y lo conversamos en diferentes oportunidades, talleres, inauguraciones, encuentros, intercambios.
En este caso retomamos algunas de las expresiones que se enunciaron y dan sentido a mucho de lo que se viene construyendo colectivamente, donde cada expresión es signo de las resistencias que se ven cotidianamente y que la comunicación nos posibilita contarlas además de vivirlas.

Patricia, una de las comunicadoras rurales decía:

Somos pueblos de agricultores. La radio nos permite dar a conocer nuestros acuerdos sobre los precios de venta y compra, tener información de los mercados, ya no puede venir alguien y decirnos algo que no es La radio es un sueño, ponerla al servicio de la comunidad, que cada uno ofrezca lo que tiene. $^{15}$

Para Demetrio, tener la radio

abrió muchas puertas, podemos expresarnos, ser libres, tener nuestra información, contar lo tranquilo de nuestro lugar, las cosas que nos pasan, nuestras noticias. Nos da fuerza de expresar, de defendernos, siempre nos han callado, no nos dejaron hablar. Como pueblo diaguita calchaqui nuestra idea es resaltar nuestra voz, de aquí no nos calla nadie, ese es nuestro derecho a expresarnos, y vamos a seguir creciendo y luchando para adelante. ${ }^{16}$

En la quebrada de Escoipe expresaban que como pueblos originarios y agricultores

15 Testimonio de Patricia, floricultura, y comunicadora rural. Integrante de la comparsa Los Caprichosos. Entrevista realizada en la inauguración de la radio de El Fuerte, Jujuy, Argentina.

16 Testimonio de Demetrio Yapura. Comunicador rural, agricultor. Entrevista realizada en el encuentro Comunicación y Territorios realizado en abril 2015 en Cuchiyaco, Valle del Luracato, Salta, Argentina. 
familiares respetamos nuestra tierra y la naturaleza, es por esto que nos animamos a pensar y soñar nuestra radio como el viento, porque transmite la voz y llega a todas partes; como el territorio, nuestro lugar y lo que somos; como un trueno o un relámpago que nos alerta de la lluvia. La radio canta, nos contiene, la radio es territorio, anuncia, llega a todas partes, anuncia lo que somos, nuestra identidad. ${ }^{17}$

Otras comunicadoras populares definieron en un taller a la radio como libertad, realidad, derecho, crecimiento, compromiso, confianza en uno mismo y hacia los demás, sueño, trabajo, justicia, debate, voluntad, integración, organización, amor, solidaridad y unión. Y también es agua, porque es imprescindible como la comunicación, es «ambiente» porque es fundamental para la vida; «luz» porque ilumina y cuando no hay libertad permite ver un caminito; $y$ "aire» porque lo compartimos todos; "fuego" porque da calor a la gente que lo necesita, que no se siente bien; es "tierra" porque sin tierra no se sostiene nada, porque la tierra es vida, riqueza y sabiduría, es una "paloma blanca» porque simboliza la libertad de expresión.

\section{Resistir y reinventar con goce}

Innovación, riesgo, astucia y goce. Los espacios de creación de la radio y de enunciación son espacios fuertes donde se disputan poderes y capitales, pero son también espacios de encuentro, de risa, de descubrimiento, de creatividad y de goce. Allí se manifiestan el canto, la potencialidad creadora, el juego tecnológico, la fiesta, los relatos, las anécdotas. Aquí también encontramos los ciudadanos celebrities de los que habla Rincón (2015), en el sentido de la producción del uno mismo desde y en la demanda de

17 Producto de Taller realizado el 09 de abril de 2015 en el paraje La Zanja, Quebrada de Escoipe con los representantes de las organizaciones y comunidades en donde se trabajó el proceso de definición del proyecto político de la radio de Escoipe. Esta frase es una de las respuestas a la pregunta ¿qué significa para nosotros la radio? entretenimiento, para hacerse visible con estéticas propias, en la acción colectivista de significar junto con otros, en la afirmación de las identidades (2015, p. 37). Por eso se disfruta «ser periodista, lo vivido cuando hablamos, olvidarnos de la vergüenza, tomar coraje». Y es también el espacio del juego, de lo lúdico, de la expresión y de la producción cultural, como procesos de aprendizaje y puesta en común. Estas luchas y procesos de ciudadanías, políticas y celebrities son posibles porque los sujetos se asumen colectivamente políticos. El colectivo es la posibilidad de fortalecerse, en los procesos de toma del poder hecho palabra, lo que se manifiesta en las tres experiencias que elegimos contar.

La agricultura familiar, con sus organizaciones campesinas y las comunidades indígenas, busca la visibilidad y la conquista de derechos desde diferentes estrategias y campos de acción. Algunas leyes $^{18}$ consiguieron pero actualmente cada una de ellas está en las mismas condiciones de fragilidad que la de comunicación que aquí abordamos. En aquella coyuntura (2019 al 2015) se buscó impulsar medios de comunicación popular, comunitarios e indígenas en ámbitos rurales, lo que significaba generar espacios donde fuera posible visibilizar sus luchas. Al mismo tiempo, estos espacios revisten de un valor educativo fundamental, por cuanto que posibilitan la «toma de la palabra», como parte del ejercicio pleno de la ciudadanía en la participación

18 Solo para nombrar algunas recordamos en el marco nacional la Ley de Reparación Histórica de la Agricultura Familiar; Ley de Servicios de Comunicación Audiovisual (que contempla específicamente a los actores de pueblos originarios); Ley del Trabajador Rural; Ley de Bosques; Ley de Tierras en Manos Extranjeras. Los monotributos sociales para agricultores familiares que están $100 \%$ subsidiados y permiten acceder a obra social y aportes jubilatorios a mujeres y hombres mayores de 18 años que trabajan en la agricultura familiar en todo el país. La Ley 26160 de relevamiento de tierras indígenas. Y en el plano provincial no es menor que en Salta surgiera del movimiento de organizaciones campesinas y pueblos originarios la primera Ley de Agricultura Familiar del país, bajo el nombre de Felipe Burgos, quien fue un referente y funcionario del gobernador Ragone, desaparecido en el último golpe cívico militar. Burgos era antes de su secuestro y dinamización en febrero de 1976 un luchador popular y dirigente campesino, fundador de la Federación Única de Sindicatos de Trabajadores Campesinos y Afines -FUSTCA-. 
de los asuntos públicos.

Los medios de comunicación contribuyen doblemente a la construcción de la ciudadanía: ofrecen un potencial educativo por el proceso y por el contenido de los mensajes que transmiten. Por sus contenidos pueden dar lugar a la socialización del legado histórico, del conocimiento; pueden facilitar la comprensión de las relaciones sociales, de los mecanismos de la estructura del poder (comprender mejor las cosas de la política), de los asuntos públicos del país; pueden esclarecer los derechos de la persona humana y discutir los problemas locales. (Krohling, 2001, p. 89).

Pensar construir sus medios es en realidad reforzar esa «toma de la palabra» que ya había sido iniciada al conformarse como organizaciones y disputar diferentes líneas de apoyo del Estado. Estos medios, "sus medios», aportan como proceso, ya que contribuyen a la construcción de un discurso propio, al fortalecimiento de las identidades, a la puesta en común y sobre todo a la participación y articulación de diferentes actores de una comunidad y de otras comunidades con el fortalecimiento y participación de redes y luchas que van más allá de los alcances de sus antenas.

Resulta complejo pensar las consideraciones finales sin recuperar algunas precisiones que nos acerca Alfonso Gumucio Dagron sobre la importancia de los «nuevos comunicadores», quienes

deben tener conocimiento de las discusiones de desarrollo (que para nosotras, con solo tener conocimiento no es suficiente, es necesario una lectura crítica y un replanteo de paradigma efectivamente), la experiencia directa de trabajo en las comunidades, la sensibilidad para abordar la interculturalidad y el conocimiento de los medios y las tecnologías, [ ] sin sucumbir a la fascinación por ella, tomándola como una herramienta para apoyar el proceso de la comunicación humana y no se debe en ningún caso depender de la misma. El comunicador debe entender que la comunicación para el cambio social está relacionada íntimamente con la cultura y el diálogo, y que se requiere sensibilidad y compromiso para apoyar el proceso de cambio [ ] es un proceso de diálogo privado y público, a través del cual los participantes deciden quiénes son, qué, quieren y cómo pueden obtenerlo. (2004, p 20).

No es desde «la comunicación para el cambio social» desde donde nos ubicamos; sin embargo, creemos que hay muchas de estas características que son válidas de recuperar para la comunicación transformadora, comunitaria, popular e indígena que se expande por los rincones rurales de nuestro amplio y diverso territorio.

Es un camino que no solo se debe transitar en el campo, sino también en las reflexiones académicas que nos encuentran en este tipo de publicaciones y encuentros, por ejemplo. Pues creemos que

si bien en América Latina lleva muchas décadas de experiencias de comunicación popular y participativa, esto no se ha reflejado ni en los estudios académicos ni en muchas de las carreras de comunicación. Es un vacío que fue llenado mal o bien por las ong que trabajan proyectos de desarrollo comunitario. Pero las universidades se han mantenido al margen de los procesos de comunicación dialógica en la sociedad, ya que sus apuestas siempre fueron los medios masivos de comunicación, el sector privado mediante las relaciones públicas o publicitarias. (Gumucio Dagron, 2004, p. 16).

Las instancias de discusión y planificación desde y 
con «los territorios» permiten seguir apostando al fortalecimiento de las identidades locales, asegurando el arraigo y la continuidad de los procesos comunitarios. Lo que les posibilita a las distintas organizaciones reconocerse, conectarse y apropiarse del medio, como otra forma de encuentro y participación, entendiendo que todo esto suma a un ejercicio de una ciudadanía plena en nuestras ruralidades. Es necesario para nuestro campo y esta región contribuir en escribir y enunciar otros relatos, partiendo desde otras concepciones. Puede ser un punto de partida clarificador y oxigenante el que nos acerca Contreras, cuando dice que:

para abordar las relaciones de la comunicación con el vivir bien debemos empezar pensando en experiencias comunitarias individuales y colectivas que partan de cuatro nociones básicas: 1) saber escuchar; 2) saber compartir; 3) saber vivir en armonía y complementariedad; y 4) saber soñar. (2014, p. 24).

Desde allí, tomamos este trabajo como un principio para seguir soñando y seguir haciendo, dando un lugar fundamental a la alegría de la construcción colectiva, porque como decía Jauretche, nada grande se puede hacer desde la tristeza. Y tomar la palabra siempre es un acto de grandeza.

El arte de nuestros enemigos es desmoralizar, entristecer a los pueblos. Los pueblos deprimidos no vencen. Por eso venimos a combatir por el país alegremente. Nada grande se puede hacer con la tristeza. (Jauretche, 2012, p. 53)

\section{Referencias}

Alcoba, L. y Chávez, F. (2014). La agricultura familiar en el NOA: provincia de Salta. Posta de Hornillos, Jujuy: Ediciones Inta.

Becerra, M., y Mastrini, G. (2006). La concentración mediática Argentina: de eso no se habla.
Buenos Aires: Centro de Estudios Legales y Sociales -CELS-.

Contreras, A. (2014). De la comunicacióndesarrollo a la comunicación para el vivir bien. Boletín informativo Spondylus de la Universidad Andina Simón Bolívar, sede Ecuador, Quito.

Escobar, A. (1996). La problematización de la pobreza: la fábula de los tres mundos y el desarrollo. La invención del Tercer Mundo-Construcción y deconstrucción del desarrollo. Bogotá: Norma.

García, A. y Burgos, R. (2011). El puente y las piedras. Rearticulación del espacio audiovisual en el Programa de Polos y Nodos Audiovisuales del Sistema Argentino de Televisión Digital Terrestre: el caso del Nodo Jujuy. Ponencia presentada en el xiI Congreso Ibercom. Santa Cruz de la Sierra: Universidad Privada de Santa Cruz de la Sierra.

Kejval, L. (2014). Radios comunitarias, populares y alternativas: reflexiones, preguntas y desafíos a partir de la institucionalización de la demanda por democratizar las comunicaciones. En L. Bergesio, R. Burgos y C. González (compiladores). Mapas comunicacionales y territorios de la experiencia. xV Congreso de Redcom. Jujuy, Edinju.

Krohling, C. (2001). Comunicación comunitaria y educación para la ciudadanía. Revista Signo y Pensamiento 38, 82-93. Pontificia Universidad Javeriana.

Mata, M. (2015). Los lugares incómodos (o las deudas-desafíos de las carreras de Comunicación). Chasqui. Revista Latinoamericana de Comunicación 129, 17-35.

Mata, M. (2009). Comunicación comunitaria en pos de la palabra y la visibilidad social. En Área de Comunicación Comunitaria (compiladores): Construyendo 
comunidades Reflexiones actuales sobre comunicación comunitaria. Buenos Aires: La Crujía y Universidad Nacional de Entre Ríos.

Mata, M. (1987). Cuando la comunicación puede ser sentida como propia, en AAvv, Comunicación y culturas populares en Latinoamérica, Felafacs-G. Gilli, México, 1987.

Mata, M. (1988). Comunicación popular de la exclusión a la presencia. Córdoba: Mimeo.

Mata, M. (1994). Nociones para pensar la comunicación y la cultura masiva. Buenos Aires, Centro de Comunicación Educativa La Crujía.

Martín Barbero, J. (1987). De los medios a las mediaciones, comunicación, culturay hegemonía. Barcelona, Gustavo Gilli.

Martín Barbero, Jesús. (1983). Comunicación popular y los modelos trasnacionales. En Chasqui 8, CIESPAL, Quito.
Martín Barbero, Jesús. (2003). La educación desde la comunicación. Bogotá: Norma.

Rincón, Omar. (2015). Lo popular en la comunicación: Culturas bastardas + culturas celebrities. En Adriana, Rincón y Omar (Ed.), La comunicación en Mutación, Remix de discursos. Amado,. Centro de Competencia en Comunicación para América Latina, C3 FES, Colombia, Bogotá.

Rodríguez, Clemencia. (2011). Trayectoria de un recorrido: comunicación y cambio social en América Latina. En Prerira G, José Miguel, Cadavid B, Amparo (Ed.), Comunicación, desarrollo y cambio social, interrelaciones entre comunicación movimientos ciudadanos y medios. Bogotá: Editorial Pontificia Universidad Javeriana.

Villamayor, C. (2014). Las radios comunitarias, gestoras de procesos comunicacionales. Buenos Aires, 2011 - 2014. Mediaciones 12, 88 - 105. Bogotá.

\section{María Laura Agüero}

marialauraaguero@gmail.com

UNSa-INTA.

Ana Müller

anamuller07@gmail.com

UNSa-Secretaria de Agricultura Familiar. Salta, Argentina.

Artículo derivado del proyecto Nacional Fortalecimiento de las tramas sociales y la gobernanza territorial. - Instituto Nacional de Tecnología Agropecuaria. PNSEPT-1129042. Proyecto de investigación tipo B n 2393: Comunicación popular, alternativa y comunitaria en la provincia de Salta. Historización, reconfiguración y transformación de otras experiencias comunicacionales. Facultad de Humanidades, Consejo de Investigaciones Universidad Nacional de Salta. Resolución 287-2016-CCI. 